\title{
GPS tracking of Red Kites (Milvus milvus) reveals fledgling number is negatively correlated with home range size
}

\author{
Thomas Pfeiffer $^{1} \cdot$ Bernd-Ulrich Meyburg ${ }^{2}$
}

Received: 28 July 2014/Revised: 30 March 2015/ Accepted: 30 April 2015/Published online: 15 May 2015

(C) The Author(s) 2015. This article is published with open access at Springerlink.com

\begin{abstract}
To date, reliable studies on the spatial area use and home range size of the Red Kite (Milvus milvus) during the breeding season are lacking. Between 2007 and 2014, 43 adult individuals were fitted with GPS transmitters in Germany. The home range sizes of 27 males, which successfully reared 47 broods, ranged between 4.8 and $507.1 \mathrm{~km}^{2}$ based on the $95 \%$ kernel utilization distribution. The median during the nestling and post-fledging dependent periods was $63.6 \mathrm{~km}^{2}$. The home ranges of 12 females, with a total of 21 successful broods, ranged between 1.1 and $307.3 \mathrm{~km}^{2}$. Within a single breeding season, there were considerable differences among home range sizes. There was also considerable variation in the home range size of adults during the course of a season. Across years, the median home range size of all males ranged between 21 and $186 \mathrm{~km}^{2}$, depending on prey availability. For individual males at the same nest site, the home range size varied up to a factor of 28 across years. Kites with very large home ranges had only one fledgling, which indicates that resources were scarce. Individuals with more nestlings had intermediate-sized to small home ranges. The relationship between the number of fledged young and home range size was modelled using a cumulative logit model. Fifty-six, 37, and $26 \%$ of male kite fixes were beyond a 1, 1.5 , and $2 \mathrm{~km}$ radius around the nest, respectively. Birds with very small or very large home ranges differed
\end{abstract}

Communicated by O. Krüger.

Bernd-Ulrich Meyburg

BUMeyburg@aol.com

Rosenweg 1, 99425 Weimar, Germany

2 World Working Group on Birds of Prey (WWGBP), Wangenheimstr. 48, 14193 Berlin, Germany considerably from these average figures. Adults sometimes travel very long distances to visit distant grasslands during and shortly after mowing (up to more than $34 \mathrm{~km}$ ) from the nest, due to the increased likelihood of prey availability at these sites. In conclusion, home rage size serves as a useful indicator of Red Kite habitat quality, which may provide key conservation information at the wider ecosystem level.

Keywords Home range size - Number of fledglings . GPS tracking · Telemetry · Red Kite Milvus milvus

\section{Zusammenfassung}

GPS-Telemetrie beim Rotmilan (Milvus milvus) zeigt negative Korrelation zwischen Jungvogelzahl und Aktionsraumgröße

Über die Raumnutzung und die Aktionsraumgröße beim Rotmilan (Milvus milvus) während der Fortpflanzungsperiode gibt es bisher keine verlässlichen Untersuchungen. 43 adulte Individuen wurden zwischen 2007 und 2014 in Thüringen mit Sendern markiert, deren Ortung mittels GPS bis auf wenige Meter genau erfolgte. Bei 27 Männchen, die 47-mal erfolgreich Jungmilane aufzogen, konnten Aktionsräume von 4,8 bis $507,1 \mathrm{~km}^{2}$ nach der Kernel $95 \%$ Methode für die Zeit der Jungenaufzucht ermittelt werden. Der Median für alle Aktionsräume der Männchen lag bei $63,6 \mathrm{~km}^{2} .12$ Weibchen mit insgesamt 20 erfolgreichen Bruten hatten home ranges zwischen 1,1 und $307,3 \mathrm{~km}^{2}$. Es bestanden sehr große Unterschiede hinsichtlich der Größe der genutzten Flächen sowohl zwischen den verschiedenen Altvögeln in jeweils demselben Jahr, als auch bei den einzelnen Tieren im Verlauf einer Brutperiode. Beim Vergleich verschiedener Jahre mit unterschiedlicher Nahrungsverfügbarkeit schwankten die jährlichen 
Medianwerte der Aufenthaltsräume aller telemetrierten Männchen zwischen 21 und $186 \mathrm{~km}^{2}$. Auch für einzelne Vögel an ein und demselben Brutplatz änderte sich die Größe der in den verschiedenen Jahren genutzten Fläche bis um den Faktor 28. Bei Milanen mit sehr großen Aktionsräumen wurde nur ein Jungvogel flügge, was für suboptimale Nahrungsverfügbarkeit spricht. Individuen mit mehreren Jungen hatten mittlere und kleine Aufenthaltsräume. Unter Anwendung eines kumulativen Logit-Modells konnte der Zusammenhang zwischen der Anzahl der flügge gewordenen Jungmilane und der Aktionsraumgröße nachgewiesen und modelliert werden. $56 \%$ der Ortungen der Männchen erfolgten außerhalb eines $1 \mathrm{~km}$-Radius um den Horst, $37 \%$ weiter als $1,5 \mathrm{~km}$ und $26 \%$ weiter als $2 \mathrm{~km}$ vom Nest entfernt. Vögel mit sehr kleinen oder sehr großen Aktionsräumen weichen deutlich von diesen Mittelwerten ab. Um entfernt liegende Flächen, die gerade gemäht werden oder wurden, aufzusuchen, entfernen sich die Altvögel teilweise sehr weit (bis zu $34 \mathrm{~km}$ ) von ihren Horsten, um die Chancen Nahrung zu finden zu erhöhen. Die Aktionsraumgröße ist ein Indikator für die Habitatqualität, der wichtige Informationen für den Artenschutz und darüber hinaus für den Schutz von Ökosystemen liefern kann.

\section{Introduction}

The Red Kite (Milvus milvus) breeds almost exclusively in Europe, and has a total population 20,800-25,500 pairs (Aebischer 2009), of which about half breed in Germany. This species is listed in Annex I of the European Union (EU) Birds Directive, and so is afforded special protection status. This bird of prey has been well studied in many of the counties that fall within its relatively small distribution range, and it is the focus of special conservation and monitoring programmes. It is also often cited as being representative of other birds that inhabit the open countryside, when considering the ecological impact of human interference on the landscape. The size and form of this raptor's home range-defined as the area in which an animal lives and moves (Burt 1943) —and the pattern of spatial use in this area represent important key parameters.

Previous studies investigating the home range size and spatial area use of the Red Kite have been based on either direct field observations (Porstendörfer 1994, 1998; Walz 2008) or a combination of observation and terrestrial very high frequency (VHF) telemetry (Nachtigall et al. 2010; Nachtigall and Herold 2013). Since 2007, it has become possible to construct devices that are small and light enough to be carried by Red Kites, with such devices also incorporating a global positioning system (GPS) receiver that automatically records the exact position of the bird independent of the time-consuming efforts by one or more observers to track animals using VHF. Thus, for the first time, it has become possible to record the spatial use of larger numbers of successfully breeding adults with great precision over long periods of time by means of a very high number of GPS fixes. Yet, to date, only Mammen et al. (2014) have tracked a single successfully breeding male.

Here, we focus on testing the hypothesis that home range size affects the number of fledglings per successful nest. Unsuccessful breeding attempts were not taken into consideration because nestlings are sometimes lost due to other factors (e.g. predation) that are independent of home range size and habitat quality. We also examine whether home range size is correlated with food availability, onset of incubation, and occupancy rate of a territory. Our results are expected to provide spatial information about the requirements of Red Kites to breed successfully, which would help conservation managers identify and protect optimal habitats.

\section{Methods}

\section{Telemetry}

From 2007 to 2014, 43 breeding adult Red Kites (29 males, 14 females) were fitted with solar-powered GPS transmitters in an area with a population density of 8.4 pairs per $100 \mathrm{~km}^{2}$ near Weimar $\left(50^{\circ} 59^{\prime} \mathrm{N}, 11^{\circ} 19^{\prime} \mathrm{E}\right.$, Thuringia, Germany). These units provided more than 329,000 GPS fixes by the autumn of 2014. Gender was determined from morphological characteristics (wing length, body mass, and brood patch; Pfeiffer 2009), which was always confirmed by bird behaviour. The males were of particular interest for the evaluation of space use during the breeding period, because they normally bear the main burden of food provision for the young. Age was known for 13 of the 43 Red Kites when fitted with transmitters because these birds had been ringed as nestlings.

Two types of transmitters were employed in the study. All transmitters weighed less than $26 \mathrm{~g}$ and were attached to the bird's back using a harness made of Teflon ribbon (Meyburg and Fuller 2007).

Details about the trapping of adult birds, fitting of transmitters, and data transmission via the Argos System are presented in Pfeiffer and Meyburg (2009) and Meyburg and Meyburg (2013). From 2007 to 2012 transmitters made by Microwave Telemetry, Inc. (USA) (www.micro wavetelemetry.com) were used. The tags were programmed to send a GPS fix every hour, except during the 
hours of darkness, provided that the battery was adequately charged. In general, the longer the sun shone and the more the bird flew, the more fixes were received. When females were incubating or sheltering the young, the batteries received scarcely any charge; consequently, no, or far fewer, fixes were received for females compared to the males during the same period.

From 2012 onwards, GPS solar radio frequency (RF) tags from e-obs GmbH (Germany) (www.e-obs.de) were also deployed. The fixes from these units were not transmitted by satellite, but had to be read out with a hand receiver in the vicinity of the bird. These units delivered about 10 times as many daily fixes and, with adequate sunshine, at 5-min intervals.

In this study, Red Kites were numbered in the order of transmitter fitting, from 01 to 43 . After a hyphen, the sex ( $\mathrm{M}$ or F) is given, followed by the type of transmitter ( $\mathrm{S}$ satellite transmitter, $\mathrm{T}-\mathrm{RF}$ tag).

Microwave Telemetry, Inc., states a GPS fix positional accuracy of $\pm 18 \mathrm{~m}$ longitude and latitude. Our test measurements show that the e-obs tags achieved similar accuracy.

Only the fixes during the daily activity phase of birds were evaluated to calculate the home range and other parameters. As the birds did not always roost in the same location, algorithms based on daily local sunrises and sunsets were used to determine the roost sites. If a bird's initial morning movement was more than $200 \mathrm{~m}$ from the roost, the start of the daily activity phase was assumed. Conversely, the last fix of more than $200 \mathrm{~m}$ from the night roost was taken to represent the end of the daily activity phase.

\section{Occupation rate of nesting territories}

Occupancy is defined as the number of years in which nesting territories are occupied, and has been studied in the target population since 1985. All nest sites of Red Kite breeding pairs in a $597 \mathrm{~km}^{2}$ study area around Weimar have been localised, the majority of chicks ringed, and the number of fledged young recorded. Based on these data, it was possible to establish how often in the past a nesting territory-defined as a confined area where nests are found and where no more than one pair is known to have bred at one time (Steenhof and Newton 2007)—was used by Red Kites fitted with transmitters. A nesting territory was considered to be occupied if an incubating adult was observed on the nest or if there were other indications of breeding. Only data from 1994 to 2014 were evaluated, to exclude any influences that gradually occur as a result of major changes in land use in East Germany following the political changes in 1990 (George 1995).

\section{Analysis of the nutritional condition of young Red Kite nestlings}

To judge the extent to which Red Kite nestlings were nourished (i.e. above or below average), the body masses of 1661 ringed young were recorded from 1989 to 2014. As the body mass development of young birds is markedly dependent on the amount of food consumed, the nutritional condition of an individual bird may be deduced by comparing its body mass against the average mass of birds from the same age class (Pfeiffer 2000). The age of young birds may be determined quite accurately from wing length (Traue and Wuttky 1966). Wing growth is minimally influenced by poor nutrition, disease, and parasites (Mammen and Stubbe 1995). Our own studies, which involved multiple checks of the same nest, have confirmed this observation, showing rare deviations of 2 days at most from the average wing growth curve.

\section{Modelling spatial area use}

Various models were tested to provide the most accurate representation of home range. The most useful model proved to be the kernel density estimation according to Worton (1989). Hovey's (1999) Home Ranger 1.5 programme was used for the calculation. Only the adaptive kernel method, using the reference value for the smoothing parameter, provided a coherent contour of the $95 \%$ kernel utilization distribution (KUD), and was considered suitable for the analysis of home range sizes. The area delimited by the $95 \%$ KUD was used in this study as the measure for home range size. The disadvantage of choosing this smoothing parameter is that over-smoothing of the areas in the outer zones occurs (Seaman and Powell 1996). The resulting calculated home range area tends to be too large. Therefore, Tables 1 and 2 also present the MinimumConvex-Polygon for $95 \%$ of the fixes closest to the nest (MCP $95 \%$ ) using the Anatrack Ltd. Ranges 8 programme (Kenward et al. 2008). Although the MCP method provides smaller area values, it does not depict the actual shape of the area covered.

In addition to comparing the home ranges of different individuals and their spatial area use in different years, changes in home range sizes during different periods of a reproductive phase were recorded. During the study, the onset of these periods varied considerably in different years. There were also variations for individual breeding pairs within the course of a year. Therefore, a differentiated calculation of these time periods was made for each nest site every year.

Starting with the date of hatching $(\mathrm{H})$ of the oldest nestling (determined by wing length measurements during 
Table 1 Home range size of male Red Kites with the breeding success being calculated for the nestling and post-fledging dependent period

\begin{tabular}{|c|c|c|c|c|c|}
\hline Transmitter no. & $\begin{array}{l}\text { Time frame of food provision } \\
\text { for young ( } 75 \text { days) }\end{array}$ & $\begin{array}{l}\text { No. of GPS } \\
\text { fixes }\end{array}$ & $\begin{array}{l}\text { Home range } \\
\left(\mathrm{km}^{2}\right)\end{array}$ & $\begin{array}{l}\text { MCP } 95 \% \\
\left(\mathrm{~km}^{2}\right)\end{array}$ & $\begin{array}{l}\text { No. of fledged } \\
\text { young }\end{array}$ \\
\hline 24-MS & $18.05 .2013-01.08 .2013$ & 705 & 4.8 & 2.4 & 1 \\
\hline 05-MS & 15.05.2009-29.07.2009 & 476 & 7.2 & 5.8 & $\geq 2$ \\
\hline 28-MT & (-27) 02.06.2012-01.07.2012 (-19) & 1205 & 7.7 & 6.6 & 3 \\
\hline 18-MS & $07.05 .2012-21.07 .2012$ & 581 & 10.2 & 7.2 & $\geq 1$ \\
\hline 07-MS & (-23) 04.06.2009-26.07.2009 & 514 & 10.9 & 7.5 & 2 \\
\hline 24-MS & 07.05.2014-21.07.2014 & 753 & 10.9 & 3.0 & 2 \\
\hline 07-MS & $05.05 .2010-23.06 .2010$ & 295 & 12.0 & 6.6 & $\geq 2$ \\
\hline 16-MS & 02.06.2012-12.08.2012 & 410 & 12.6 & 3.5 & $\geq 1$ \\
\hline 05-MS & 14.05.2010-19.07.2010 & 69 & 13.8 & 3.3 & 3 \\
\hline 29-MS & (-26) 02.06.2012-20.07.2012 & 328 & 15.5 & 9.3 & 3 \\
\hline 22-MS & (-28) 12.06.2011-29.07.2011 & 298 & 19.3 & 9.3 & 1 \\
\hline 27-MT & (20) 27.05.2012-21.07.2012 & 6104 & 21.3 & 10.3 & 3 \\
\hline 41-MT & (-16) 31.05.2014-29.07.2014 & 3681 & 22.9 & 13.4 & 1 \\
\hline 23-MS & (-38) 12.06.2011-19.07.2011 & 401 & 25.9 & 13.5 & 2 \\
\hline 18-MS & 30.06.2010-20.07.2010 & 102 & 27.6 & 12.1 & $\geq 2$ \\
\hline 34-MT & (-16 07.06.2013-05.08.2013 & 10,214 & 31.5 & 28.5 & 2 \\
\hline 10-MS & (-42) 24.06.2009-27.07.2009 & 103 & 33.7 & 12.2 & 2 \\
\hline 23-MS & 01.05.2012-15.07.2012 & 732 & 38.6 & 27.7 & $\geq 1$ \\
\hline 37-MT & $04.05 .2014-18.07 .2014$ & 15,091 & 39.7 & 38.7 & 3 \\
\hline 34-MT & 06.05.2014-20.07.2014 & 3768 & 40.3 & 30.6 & 2 \\
\hline 26-MT & (-13) 26.05.2012-27.07.2012 & 5220 & 46.7 & 29.4 & 4 \\
\hline 22-MS & $05.05 .2012-24.06 .2012(-26)$ & 344 & 58.8 & 34.4 & 1 \\
\hline 16-MS & (-48) 27.06.2010-24.07.2010 & 175 & 60.6 & 20.2 & 2 \\
\hline 17-MS & $23.05 .2011-05.08 .2011$ & 474 & 63.6 & 26.9 & 1 \\
\hline 08-MS & (-32) 09.06.2009-22.07.2009 & 426 & 66.7 & 20.1 & 2 \\
\hline 01-MS & (-41) 17.06.2007-21.07.2007 & 191 & 79.4 & 36.3 & 2 \\
\hline 21-MS & (-36 04.06.2011-13.07.2011 & 322 & 90.5 & 21.0 & 3 \\
\hline 27-MT & $16.05 .2014-30.07 .2014$ & 9053 & 92.5 & 55.8 & 2 \\
\hline 36-MT & (-24) 15.06.2013-05.08.2013 & 8755 & 94.2 & 88.2 & 2 \\
\hline 14-MS & (-40) 22.06.2010-26.06.2010 (-31) & 25 & 96.1 & 17.9 & 1 \\
\hline 09-MS & (-33) 14.06.2009-25.07.2009 & 215 & 96.7 & 44.8 & $\geq 1$ \\
\hline 32-MS & (-21) 23.06.2012-31.07.2012 & 124 & 106.7 & 32.3 & 2 \\
\hline 35-MT & 12.05.2014-26.07.2014 & 9566 & 122.9 & 187.4 & 2 \\
\hline 09-MS & 14.05.2010-28.07.2010 & 494 & 127.5 & 80.7 & 1 \\
\hline 23-MS & $17.05 .2014-31.07 .2014$ & 473 & 134.0 & 77.7 & 1 \\
\hline 37-MT & (-30) 16.06.2013-31.07.2013 & 6095 & 167.2 & 132.3 & 2 \\
\hline 20-MS & (-16 03.06.2011-30.07.2011 & 567 & 199.2 & 86.6 & 2 \\
\hline 33-MT & (-10) 06.06.2013-10.08.2013 & 3878 & 204.7 & 141.9 & 2 \\
\hline 23-MS & $19.05 .2013-02.08 .2013$ & 703 & 222.3 & 95.8 & $\geq 1$ \\
\hline 35-MT & (-17) 12.06.2013-09.08.2013 & 7241 & 258.0 & 210.7 & $\geq 1$ \\
\hline 24-MS & (-35) 13.06.2011-23.07.2011 & 460 & 265.2 & 124.0 & 1 \\
\hline 17-MS & (-27) 28.06.2010-14.08.2010 & 253 & 307.5 & 159.0 & 1 \\
\hline 10-MS & 17.05.2010-29.07.2010 & 132 & 319.9 & 104.8 & 1 \\
\hline 29-MS & 01.06.2013-14.08.2013 & 782 & 340.4 & 166.8 & 1 \\
\hline 43-MT & (-16) 01.06.2014-30.07.2014 & 10,243 & 413.3 & 234.6 & 1 \\
\hline 29-MS & $10.05 .2014-24.07 .2014$ & 573 & 432.0 & 159.9 & 2 \\
\hline 18-MS & 08.05.2011-22.07.2011 & 645 & 507.1 & 195.4 & 1 \\
\hline
\end{tabular}

Column 2 shows the period for which GPS fixes are available within this time frame. Where fixes are not available for the complete time frame, the preceding values in parentheses indicate the number of days after hatching before the bird was fitted with a transmitter. The numbers in parentheses after the time frame show the number of days from the death of two males to the end of the post-fledging dependent period. The area size calculated by the MCP $95 \%$ method is also shown as an alternative. The number of fledged young is shown as minimum values $(\geq)$ when it was not possible to access the nest 
Table 2 Home range size of Red Kite females and their breeding success calculated for the period when large young are in the nest plus the post-fledging dependent period

\begin{tabular}{|c|c|c|c|c|c|}
\hline Transmitter no. & $\begin{array}{l}\text { Time frame when large young are in nest plus } \\
\text { post-fledging dependent period ( } 50 \text { days) }\end{array}$ & $\begin{array}{l}\text { No. of GPS } \\
\text { fixes }\end{array}$ & $\begin{array}{l}\text { Home range } \\
\left(\mathrm{km}^{2}\right)\end{array}$ & $\begin{array}{l}\text { MCP } 95 \% \\
\left(\mathrm{~km}^{2}\right)\end{array}$ & $\begin{array}{l}\text { No. of fledged } \\
\text { young }\end{array}$ \\
\hline 15-FS & 13.06.2013-01.08.2013 & 53 & 1.1 & 0.3 & 1 \\
\hline $11-\mathrm{FS}$ & $28.05 .2011-16.07 .2011$ & 102 & 12.0 & 3.6 & 3 \\
\hline $15-\mathrm{FS}$ & 02.06.2014-21.07.2014 & 125 & 15.7 & 2.8 & 2 \\
\hline $11-\mathrm{FS}$ & $29.05 .2012-17.07 .2012$ & 281 & 17.7 & 7.8 & 3 \\
\hline 44-FT & $10.06 .2014-29.07 .2014$ & 1760 & 18.4 & 15.1 & 2 \\
\hline $11-\mathrm{FS}$ & 03.06.2010-22.07.2010 & 81 & 18.7 & 5.4 & 3 \\
\hline 11-FS & (26) 29.06.2009-22.07.2009 & 48 & 21.3 & 5.0 & 3 \\
\hline $12-\mathrm{FS}$ & 15.07.2010-21.07.2010 & 14 & 44.8 & 6.3 & 1 \\
\hline $12-\mathrm{FS}$ & 06.07.2011-15.07.2011 & 16 & 51.1 & 11.3 & 3 \\
\hline $42-\mathrm{FT}$ & 05.06.2014-24.07.2014 & 2019 & 52.7 & 38.0 & 2 \\
\hline $40-\mathrm{FT}$ & $22.06 .2014-10.08 .2014$ & 2223 & 60.7 & 47.2 & 1 \\
\hline 30-FS & (-11) 07.06.2012-15.07.2012 & 336 & 71.5 & 23.7 & 2 \\
\hline 38-FT & 11.06.2014-30.07.2014 & 4639 & 76.8 & 60.4 & 1 \\
\hline $15-\mathrm{FS}$ & 04.06.2011-23.07.2011 & 287 & 124.6 & 67.1 & 1 \\
\hline 25-FS & (-3) 14.06.2011-30.07.2011 & 306 & 180.3 & 110.1 & 2 \\
\hline 06-FS & (-30) 05.07.2008-24.07.2008 & 17 & 206.4 & 6.7 & $\geq 2$ \\
\hline $12-\mathrm{FS}$ & (21) 01.07.2009-28.07.2009 & 115 & 216.2 & 63.0 & 2 \\
\hline 38-FT & 27.06.2013-15.08.2013 & 4988 & 232.6 & 275.0 & $\geq 1$ \\
\hline 15-FS & (-4) 23.06.2010-07.08.2010 & 56 & 269.1 & 50.4 & 2 \\
\hline 03-FS & (25) 15.06.2008-09.07.2008 & 75 & 304.1 & 51.2 & 3 \\
\hline 19-FS & (28) 29.06.2010-20.07.2010 & 187 & 307.3 & 109.7 & $\geq 2$ \\
\hline
\end{tabular}

If transmitter fitting took place before this period, the number of days prior to this is shown in parentheses. The area size calculated by the MCP $95 \%$ method is also shown as an alternative. The number of fledged young is shown as minimum values $(\geq)$ when it was not possible to access the nest

ringing; Traue and Wuttky 1966), the different time periods were established as follows:

Courtship and territory occupancy $=1$ March to $\mathrm{H}-34$ days

Incubation period of the clutch $=\mathrm{H}-33$ days to $\mathrm{H}-1$ day

Small chicks in the nest $=\mathrm{H}$ to $\mathrm{H}+25$ days

Large nestlings in the nest $=\mathrm{H}+26$ days to $\mathrm{H}+53$ days

Post-fledging dependent period $=\mathrm{H}+54$ days to $\mathrm{H}+75$ days

In cases where it was not possible to climb to the nest, the age of young was estimated based on plumage development. The length of each of the stated time period was determined according to Wasmund (2013) and Nachtigall and Herold (2013).

The highest demand for food occurs during the period when the growing young must be fed. Therefore, the period of time from the hatching of the first chick until the young gain independence was selected as characteristic of the home range requirement of a male during the breeding season.
To compare the number of fledged young with male home ranges, home range size was only calculated for the nestling period, because the number young birds that survive after fledging cannot be determined.

The females only participate in searching for food when the young are older. Therefore, the best time for calculating the female's home range was when large young were in the nest and during the post-fledging dependent period.

\section{Statistical analyses}

All continuously scaled variables were described by the mean, standard deviation, median and the range. In case of a variable exhibiting a skewed distribution (as was the case for home ranges), the median and range (min, max) were used as descriptors.

Regression modelling was performed to investigate the influence of home range size (= independent variable in the models) on other variables (dependent variables). The link function within the model (linear link, logit link) was chosen according the types of variables. In particular, a cumulative logit model was used to determine the effects of home range size on the number of fledglings per successful 
breeding pair. Because of limited sample size, only prespecified univariable or bivariable models have been applied without further reduction or selection of variables. Correlation within the data (which may occur if data from several time points exist for individual subjects) was taken into account by applying mixed models (generalized linear mixed model (GLMM) and linear mixed models [LMM]) to investigate robustness of simple models (generalized linear model (GLM), linear model [LM]). Effects with $p$ values $<0.05$ were regarded as statistically significant. The particular models used for individual calculations are stated in the results section.

All analyses were performed using the statistical software IBM SPSS Statistics 20 and SAS 9.2 (SAS Institute Inc., Cary, NC, USA).

\section{Results}

\section{Home range size}

During the study period, 27 of the 29 males fitted with transmitters successfully raised young 47 times. The size of the home ranges used by the 29 males is shown in Table 1 . The median of all male home ranges was $63.6 \mathrm{~km}^{2}$ $\left(29.4 \mathrm{~km}^{2}\right.$ MCP $\left.95 \%\right)$, while the mean size was $114.5 \mathrm{~km}^{2}$ $\left(60.3 \mathrm{~km}^{2}\right.$ MCP $\left.95 \%\right)$. In different years, the median home range size differed; it was $33.7 \mathrm{~km}^{2}\left(12.2 \mathrm{~km}^{2} \mathrm{MCP}\right.$ $95 \%)$ in 2009; $87.3 \mathrm{~km}^{2}\left(19.1 \mathrm{~km}^{2} \mathrm{MCP} 95 \%\right)$ in 2010 ; $90.5 \mathrm{~km}^{2}\left(26.9 \mathrm{~km}^{2}\right.$ MCP $\left.95 \%\right)$ in $2011 ; 21.3 \mathrm{~km}^{2}$ $\left(10.3 \mathrm{~km}^{2}\right.$ MCP $\left.95 \%\right)$ in $2012 ; 185.9 \mathrm{~km}^{2}\left(114.0 \mathrm{~km}^{2}\right.$ MCP $95 \%)$ in 2013; and $92.5 \mathrm{~km}^{2}\left(55.8 \mathrm{~km}^{2} \mathrm{MCP} 95 \%\right)$ in 2014.

A total of 21 successful broods by 12 of the 14 females fitted with transmitters were recorded. During incubation of the clutch, and when the chicks were still small, brooding females perched on the nest or close to the nest most of the time. During this period, no fixes were usually recorded, as the batteries do not charge properly unless there is adequate flight activity. The GPS fixes resumed when the young reached 3-4 weeks in age, at which point females increasingly participated in hunting. At first, females mostly remained in visual range of the nest. Later they covered longer distances, of up to a maximum of $21.5 \mathrm{~km}$ from the nest. The median home range of females was $60.7 \mathrm{~km}^{2}$ $\left(23.7 \mathrm{~km}^{2}\right.$ MCP $\left.95 \%\right)$, while the mean home range was $109.7 \mathrm{~km}^{2}$ (45.7 km² MCP $95 \%$ ) (Table 2).

There were major differences in home range size among both males and females. Great differences were also detected among different birds within 1 year and for the same individuals across years. Figure 1 shows a major change in spatial area use for one male; in 2012, this male had a small home range of $15 \mathrm{~km}^{2}$ (three young fledged), whereas in

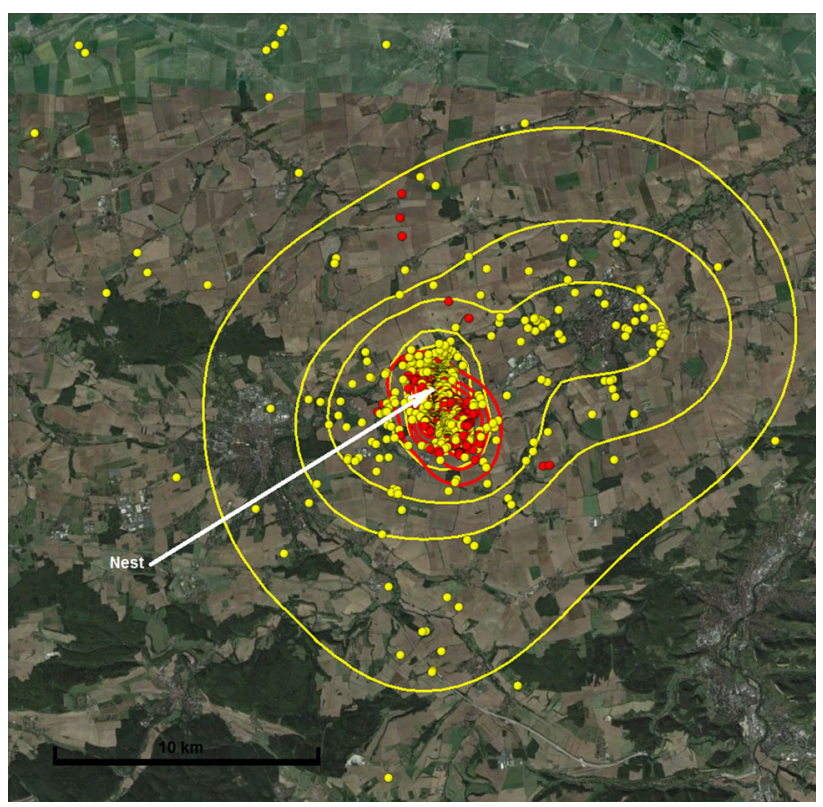

Fig. 1 Home range of Red Kite 29-MS during the provision of food to its young in 2012 (red, $15 \mathrm{~km}^{2}$ ) and 2013 (yellow, $340 \mathrm{~km}^{2}$ ) The dots represent the GPS fixes, the lines the kernel isopleths. The kernel isopleth lines mark, from the outside to the inside, the probability of stay of $95,90,85,75$, and $65 \%$. Thus, the highest utilization density is in the centre, decreasing towards the periphery

2013 the same male had a home range of $340 \mathrm{~km}^{2}$ (one young fledged). The area used in 2013 was more than 20 times larger than in 2012.

Within a single breeding period, considerable fluctuations in home range size were also detected. The home range size of all females, except one, was greatest after the young had left the nest until they gained independence. Males with medium to large sized home ranges used larger areas during the nestling and post-fledging dependency period (Fig. 2). In contrast, males with the smallest home ranges exhibited no major change or reduced the home range size further during the nestling and post-fledgling periods.

Table 3 shows the home ranges for the respective breeding period phase of all Red Kites fitted with transmitters in the study that were tracked for the complete breeding period and reproduced successfully.

\section{Number of fledglings in relation to home range size, territory occupancy rate, and onset of incubation}

The precise number of fledged young was recorded for 38 successful broods (mean 1.8, see Table 1) of males fitted with transmitters. Males with very large home ranges during the nestling period $\left(>200 \mathrm{~km}^{2}\right)$ only managed, with one exception, to rear a single young bird. The number of young per male with small or medium-sized home ranges varied between one and four. 


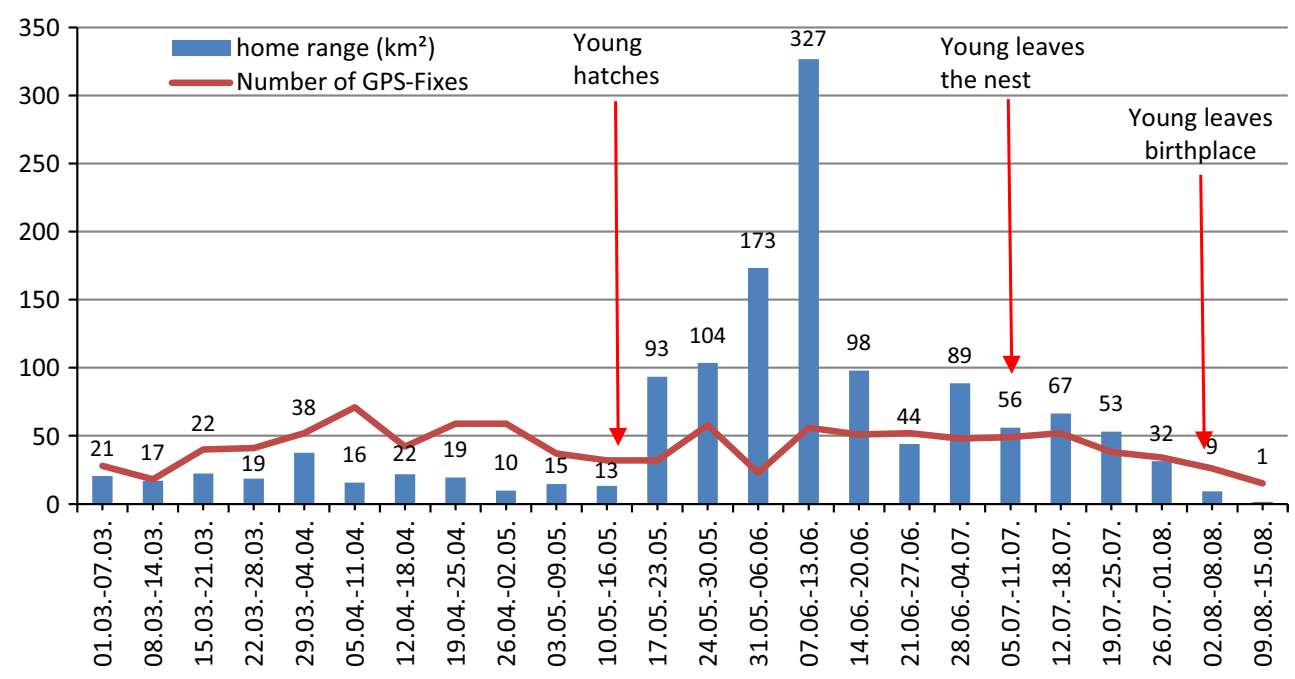

Fig. 2 Change of the weekly home range size of Red Kite 09-MS with one young in 2010

To study the dependence of the number of fledged young per successful pair on home range size, a cumulative logit model was applied. Within the model, the number of broods with three or four young was summarised, because of the low number of broods with four young. In addition, the right skewed variable "home range" was log-transformed to achieve a distribution that did not differ considerably from the normal distribution. Our results clearly show that the smaller the home range size the larger the number of young fledged. This relationship was modelled, and its significance confirmed by use of the cumulative logit model ( $p=0.0017$; Fig. 3 ). Table 4 shows the results of the model, demonstrating that if the food availability is great enough to enable the birds to use only half of the area (corresponding to -0.3 on the $\log$ scale), males are 1.92 times more likely $\left(=0.1134^{-0.3}\right)$ to rear three instead of two young or two instead of one young.

Within this model, the data were regarded as independent; however, few of the individuals contributed information in different years; specifically, we recorded two males with broods in 3 years, seven males with broods in two years, and 18 males with broods in only a single year. Therefore, the robustness of the model was tested by a sensitivity analysis using a GLMM. A $p$ value of 0.009 was obtained for the home range size related effect, demonstrating the validity of the result obtained by simple modelling.

The nesting territories were occupied two to 21 times during the 21 years of observation. The median was 10 and the mean $11.2 \pm 6.4$. If the cumulative logit model is expanded to a bi-variable model using the territorial occupancy rate as a second major influencing variable, significant relationships emerge (home range: $\mathrm{p}=0.0169$, occupancy rate: $p=0.0117)$. Thus, the number of fledged young was influenced by both home range size (negative correlation) and the territorial occupancy rate (positive correlation).

Because of limited sample size, the interaction of both influencing variables could not be investigated within the bivariable cumulative logit model, since it did not converge. Therefore, we investigated the relationship between the occupancy rate and home range size using a LMM. Both influencing factors were independent of each other, as no significant relationship was detected $(p=0.721)$.

In an additional analysis, the dependence of the number of fledged young on breeding phenology (onset of incubation) was investigated in cumulative logit models (GLMs, GLMMs). The incubation period started from 30 March to 3 May, while the median and the mean values were 15 April. The standard deviation was 8.6 days. Nearly identical effects were found in the GLM $[\mathrm{OR}=1.10$ (95\% CI: 1.01-1.21), $p=0.039$ ) and the GLMM [OR $=1.11$ [95\% CI: 0.94-1.32), $p=0.055$ ]; however, the significance of the effects was borderline.

\section{Home range size in relation to onset of incubation and food availability}

Males that started breeding early tended to use smaller home ranges than birds that started breeding late. For 30 successful broods of 21 different males, the onset of incubation was calculated from the age of the young when they were ringed. Using LMM, a correlation was confirmed between home range size and the onset of incubation $(p=0.0002)$.

For 58 nestlings belonging to 30 broods of 21 different males, the nutritional status was recorded. The nutritional 
Table 3 Home range size $\left(\mathrm{km}^{2}\right)$ of adult Red Kites during territory occupation, the incubation period of the clutch, the period when small young are in nest, the period with large young in nest, the post- fledging dependent period and the time frame from the start of dismigration of the young up to departure for winter quarters in autumn

\begin{tabular}{|c|c|c|c|c|c|c|c|c|}
\hline Transmitter no. & Year & Courtship & $\begin{array}{l}\text { Incubation } \\
\text { period }\end{array}$ & $\begin{array}{l}\text { Small } \\
\text { young }\end{array}$ & $\begin{array}{l}\text { Large } \\
\text { young }\end{array}$ & $\begin{array}{l}\text { Post-fledging } \\
\text { dependent period }\end{array}$ & Autumn & $\begin{array}{l}\text { No. of fledged } \\
\text { young }\end{array}$ \\
\hline $15-\mathrm{FS}$ & 2013 & $-(0)$ & $-(2)$ & $-(1)$ & $0.8(43)$ & 1.7 (10) & $194.6(41)$ & 1 \\
\hline 38-FT & 2014 & $13.8(441)$ & $5.0(193)$ & $12.2(1071)$ & 97 (3849) & $12.4(790)$ & $-(0)$ & 1 \\
\hline $11-\mathrm{FS}$ & 2011 & $11.7(16)$ & $-(0)$ & $2(29)$ & $2.2(38)$ & $17.3(64)$ & 39.9 (349) & 3 \\
\hline $11-\mathrm{FS}$ & 2010 & $11.3(69)$ & $0.04(16)$ & $1(11)$ & $10(14)$ & $19(67)$ & $21.5(102)$ & 3 \\
\hline $11-\mathrm{FS}$ & 2012 & $12.6(11)$ & $-(2)$ & $-(6)$ & $8(111)$ & $19.6(170)$ & $15.4(343)$ & 3 \\
\hline $15-\mathrm{FS}$ & 2014 & $-(8)$ & $-(0)$ & $-(6)$ & $0.4(80)$ & $34.5(45)$ & $5.3(15)$ & 2 \\
\hline $15-\mathrm{FS}$ & 2011 & $-(9)$ & $-(2)$ & $-(0)$ & $140.5(200)$ & 36.7 (87) & $10.8(146)$ & 1 \\
\hline 12-FS & 2010 & $-(0)$ & $-(0)$ & $-(0)$ & $-(0)$ & 44.8 (14) & 31.9 (13) & 1 \\
\hline $12-\mathrm{FS}$ & 2011 & $-(0)$ & $-(0)$ & $-(0)$ & $-(0)$ & $51.1(16)$ & $-(8)$ & 3 \\
\hline 24-MS & 2013 & $11.5(79)$ & $6.1(130)$ & 13.8 (195) & $4.1(304)$ & 1.9 (206) & $155.1(286)$ & 1 \\
\hline 05-MS & 2009 & $9.9(52)$ & $13.5(97)$ & $5.9(174)$ & $6.1(190)$ & 18.3 (112) & $26.2(228)$ & $\geq 2$ \\
\hline 18-MS & 2012 & $-(8)$ & $16.8(89)$ & 12.8 (174) & $9.9(232)$ & $8.4(175)$ & $7.1(28)$ & $\geq 1$ \\
\hline 16-MS & 2012 & 22.6 (124) & 7.7 (47) & 18.8 (138) & $14.6(182)$ & $2.2(90)$ & $6.9(28)$ & $\geq 1$ \\
\hline 24-MS & 2014 & $6.6(207)$ & $4.6(217)$ & $5.9(291)$ & 15 (269) & $11.1(193)$ & $30.1(145)$ & 2 \\
\hline 05-MS & 2010 & $6.5(54)$ & 4.9 (67) & $15.1(34)$ & $16.4(31)$ & $-(4)$ & $-(0)$ & 3 \\
\hline 07-MS & 2010 & $7.3(88)$ & $7.1(204)$ & $7.8(142)$ & $30.3(153)$ & $-(0)$ & $-(0)$ & $\geq 2$ \\
\hline 34-MT & 2014 & $-(0)$ & $-(0)$ & $5.7(654)$ & $31.5(2172)$ & $80.6(942)$ & $-(0)$ & 2 \\
\hline 37-MT & 2014 & $12.9(1102)$ & $9.2(2156)$ & $38.8(3647)$ & 44.7 (8788) & 28.7 (2656) & $6.6(1679)$ & 3 \\
\hline 23-MS & 2012 & $23.6(120)$ & $12.9(220)$ & $27.2(201)$ & $58.3(263)$ & $18.1(268)$ & 11.2 (199) & $\geq 1$ \\
\hline 23-MS & 2014 & $10.9(82)$ & $137.8(208)$ & $155.4(167)$ & $82.0(210)$ & $8.0(96)$ & $12.2(97)$ & 1 \\
\hline 22-MS & 2012 & $8.7(84)$ & $8.9(154)$ & 20.7 (194) & 84.5 (150) & $-(0)$ & $-(0)$ & 1 \\
\hline 27-MT & 2014 & 6.9 (3587) & $12.7(3861)$ & $144.8(3226)$ & $85.6(4085)$ & $59.1(1742)$ & $3.5(50)$ & 2 \\
\hline 17-MS & 2011 & 15.7 (179) & $67.2(249)$ & 34.7 (185) & $98.8(171)$ & 41.1 (118) & $16.9(361)$ & 1 \\
\hline 23-MS & 2013 & 15.7 (178) & $14.3(265)$ & $46.4(221)$ & $106.3(279)$ & 506.9 (203) & 25.9 (303) & $\geq 1$ \\
\hline 09-MS & 2010 & 24.3 (239) & $19.8(225)$ & $155.9(143)$ & $128.1(207)$ & 62.9 (144) & $10.5(94)$ & 1 \\
\hline 35-MT & 2014 & 13.5 (2809) & $21.5(3156)$ & $259.2(3758)$ & $181.8(4574)$ & 77.9 (1234) & $35.1(701)$ & 2 \\
\hline 29-MS & 2014 & $6.4(125)$ & $656.9(242)$ & $549.9(190)$ & $292.1(237)$ & $221.6(146)$ & $43.3(87)$ & 2 \\
\hline 10-MS & 2010 & $-(0)$ & $-(1)$ & 84.1 (28) & 309.3 (59) & $191.5(45)$ & $14.7(25)$ & 1 \\
\hline 18-MS & 2011 & $14.1(48)$ & $33.8(73)$ & $487.5(241)$ & 393.5 (216) & $176(188)$ & 92.2 (118) & 1 \\
\hline 29-MS & 2013 & $10.6(168)$ & $156.2(163)$ & $263.5(250)$ & $532(319)$ & $41.1(213)$ & 53.1 (194) & 1 \\
\hline
\end{tabular}

Figures in parentheses show the number of GPS fixes in each of these periods, respectively. The upper part of the table lists the females in ascending order of home range size in the post-fledging dependent period; below, the males are listed in ascending order of home range size in the period when large young are present in the nest

status was up to $41 \%$ worse and $18 \%$ better than the longtime mean of the respective age-class. The nutritional condition of the young was negatively correlated with the home range size (log transformed) of the related male based on LMMs ( $p=0.0104)$. Thus, males with wellnourished young were more likely to have a small home range. Nestlings in poor nutritional condition were more likely to belong to males with a large home range.

\section{Territory size and distances travelled for food}

Neighbouring breeding males defend an area around the nest against conspecifics ("territory" according to
Newton 1979). Outside the territories, birds may use overlapping areas when food supplies are optimal. The fixes from the end of May to mid-June 2012 of three closely neighbouring males (24-MS, 26-MT and 27-MT) are shown in Fig. 4. The kernel model shows that areas around the nest where no overlap takes place may be calculated. The $68 \%$ kernel isopleth is the boundary between 26-MT und 24-MS, and the $81 \%$ kernel isopleth is the boundary between 24-MS und 27-MT. If the areas contained within the isopleths are assumed to be the territories of the respective birds, the size of the territory for 26-MT was $1.35 \mathrm{~km}^{2}$ (68\% kernel isopleth), while it was $0.4-1.1 \mathrm{~km}^{2} \quad(68-81 \%$ kernel 


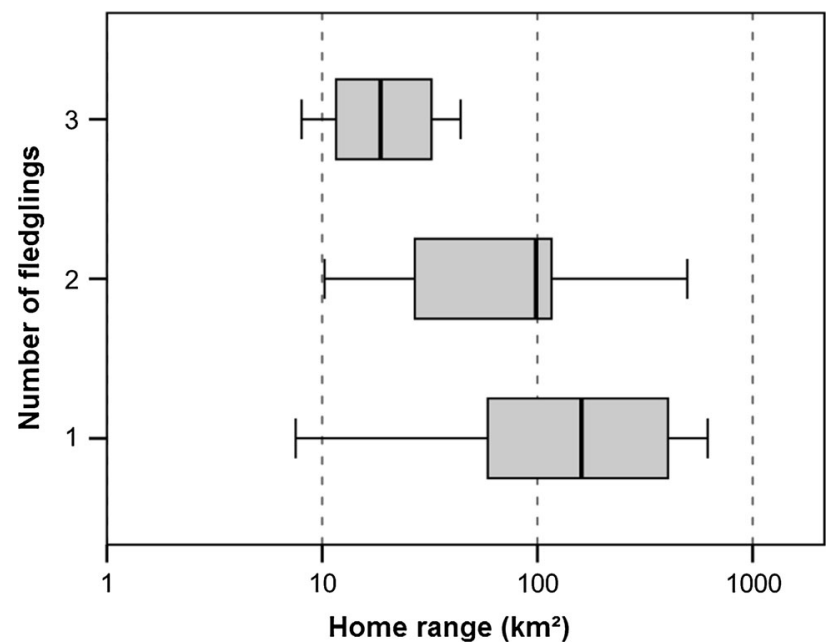

Fig. 3 Box-Whisker plot of the number of fledglings per successful breeding pair based on the dependence of the home range size. Vertical line in the box refers to median whereas the box contains the data between 25 and $75 \%$ percentiles. Note that the $x$-axis (home range size in $\mathrm{km}^{2}$ ) is log-transformed

isopleth) for 24-MS and $1.75 \mathrm{~km}^{2}$ (81\% kernel isopleth) for 227-MT. 24-MS had two different boundary isopleths, because it defended its territory against two neighbours.

Males sometimes travelled long distances from the nest to locate grasslands that had been mowed, due to an increased likelihood of locating prey at these sites. The farthest recorded distance for a male with young was $34.8 \mathrm{~km}$. Figure 5 shows the percentage share of fixes for males up to a certain distance from the nest during the period when they provide food for the young in the nest. Fixes of less than $100 \mathrm{~m}$ from the nest were not taken into account, because the kites did not tend to hunt actively in this area, but usually rested, fed on their prey or fed their young. Figure 5 presents the mean value from 67,327 fixes of 27 males with 47 successful broods (red curve), in addition to the deviations for a Red Kites with small (green curve) versus large (blue curve) home ranges.

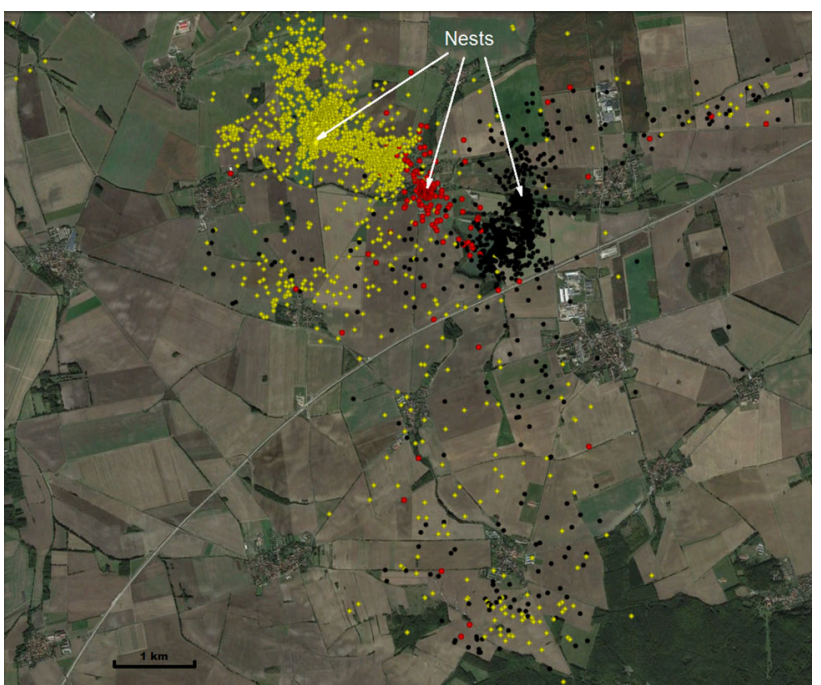

Fig. 4 Fixes of three neighbouring breeding Red Kites in 2012: 26-MT (yellow, 3100 fixes from 26/5 to $14 / 6$, home range $=43 \mathrm{~km}^{2}$, four young), 24-MS (red, 305 fixes from 20/5 to 14/6., home range $=23 \mathrm{~km}^{2}$, number of young unknown, the brood was later lost) and 27-MT (black, 1753 fixes from 27/5 to 14/6, home range size $=38 \mathrm{~km}^{2}$, three young)

\section{Discussion}

\section{Comparison of home range size findings with earlier studies}

Previously published studies already indicate considerable variation in Red Kite home range size; however, the maximum home range values obtained by the present study exceeded those obtained in previous studies. This difference is due to the considerably greater number of birds that were tracked, in addition to the automated methods of data collection when using transmitters with GPS receivers. Whilst a good overview of small home ranges may be achieved using direct observation and VHF telemetry, following the birds over long distances from the nest using these techniques is not feasible due to the large investment
Table 4 Home range size and the number of fledglings- the result for the cumulative logit model

\begin{tabular}{lllll}
\hline & Estimate & Significance $(p$-values $)$ & \multicolumn{2}{l}{$95 \%$ Confidence interval } \\
\cline { 4 - 5 } & & & Lower limit & Upper limit \\
\hline Intercept & & 0.0007 & 0.0006 & 0.1362 \\
Fledgling $=1^{\mathrm{a}}$ & 0.0140 & 0.0639 & 0.0119 & 1.1326 \\
Fledgling $=2^{\mathrm{b}}$ & 0.1161 & & 0.0291 & 0.4419 \\
Odds ratio & 0.1134 & 0.0017 & & \\
Area $^{\mathrm{c}}$ & & & & \\
\hline
\end{tabular}

\footnotetext{
${ }^{\text {a }}$ Odds to achieve two instead of one fledglings

b Odds to achieve three instead of two fledglings

${ }^{c}$ Factor due to increase of area for both types of odds (odds ratio)
} 
Fig. 5 Percentage of fixes up to a certain distance from the nest (see text for full information)

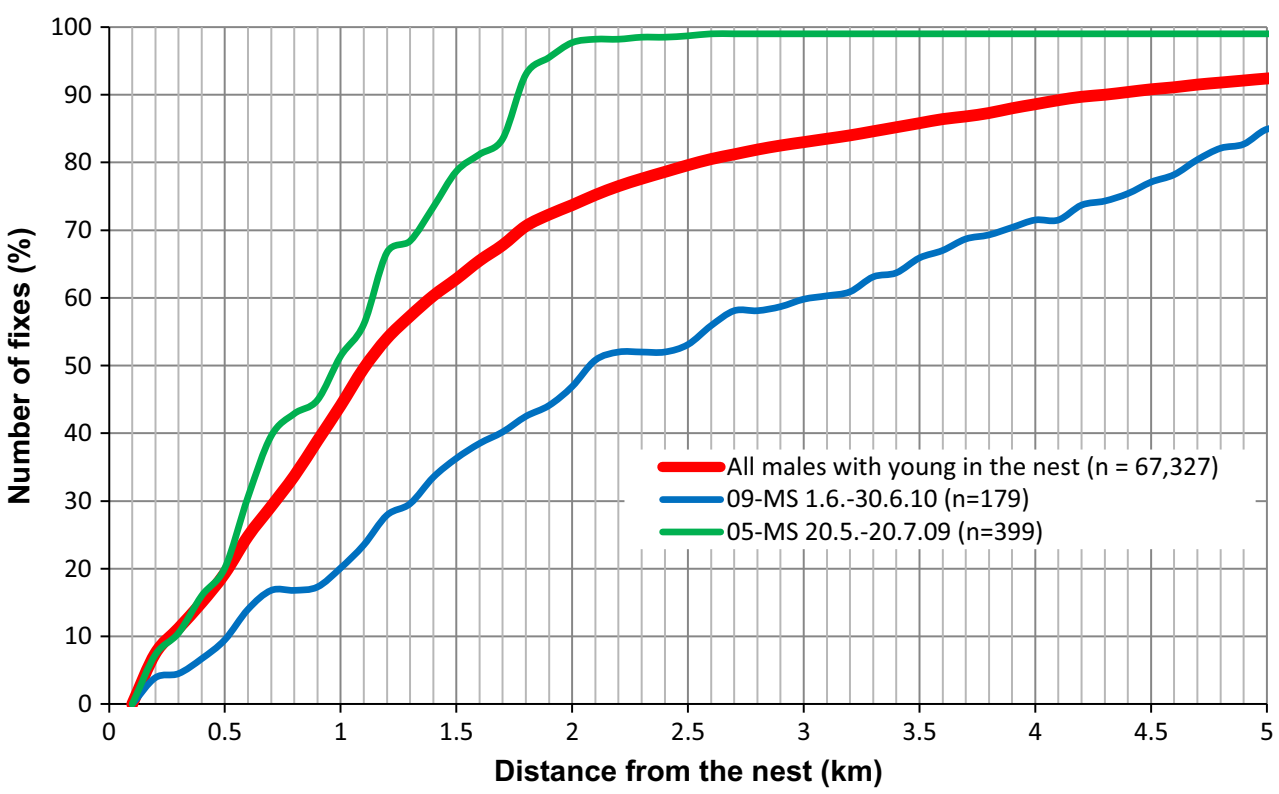

of time and human resources that would be required. Continuous and comprehensive monitoring of long-distance hunting flights is only possible using remote technology, like GPS. Consequently, existing studies based on observation or VHF do not contain all such flights distant from the nest, leading to the (incorrect) calculation of smaller home ranges.

Porstendörfer (1994) was the first to provide home range sizes of the Red Kite monitored in Southern Lower Saxony in 1992 and 1993. The author recorded a home range of about $10 \mathrm{~km}^{2}$ by sketching observed hunting flights on a map. The author recorded a home range size of $7.5 \mathrm{~km}^{2}$ for a male in a later study (Porstendörfer 1998). Walz (2001) also calculated home ranges of between 13 and $35 \mathrm{~km}^{2}$ in Baden-Württemberg by means of observation.

In 1997 and 1998, in the northeastern outland of the Harz Mountains, home ranges of $8.7,9.9$, and $38.4 \mathrm{~km}^{2}$ were obtained for successfully breeding males, while home ranges of $5.5,5.6$, and $91.6 \mathrm{~km}^{2}$ were obtained for females (all MCP $95 \%$ ) by employing a combination of terrestrial telemetry and observation (Nachtigall et al. 2010). Nachtigall and Herold (2013) conducted similar studies in East Saxony during 2002 and 2003, obtaining home range values of $9.1,10.0$, and $11.1 \mathrm{~km}^{2}$ (MCP $100 \%$ ) for three successfully breeding males in a breeding season.

Mammen et al. (2014) determined home range sizes of between 2.33 and $54.94 \mathrm{~km}^{2}$ (MCP $95 \%$ ) for four successfully breeding males. One of the males was tracked during two different years. Four successful females had home ranges of between 0.51 and $74.42 \mathrm{~km}^{2}$. Two of the females were tracked in two consecutive years. VHF telemetry was used, except in one case, when a male was fitted with a GPS tag. A total of 177 fixes were received between 6 June and 31 July 2010, and a home range of $53.19 \mathrm{~km}^{2}$ (MCP $95 \%$ ) was calculated.

\section{Number of fledglings in relation to home range size, territory occupancy rate, onset of incubation}

Kites with very large home ranges had only one fledgling, whereas individuals with more nestlings tended to have medium-sized to small home ranges. This study is the first to report a significant correlation between the number of fledglings per successful nest and home range size for the Red Kite. However, this correlation has also been detected for the Sparrow Hawk (Accipiter nisus) (Newton 1986), the conclusion of which is that lower food resource availability in the habitat leads to larger home ranges and poorer breeding performance. Our results supported this inference. The study by Newton (1986) involved nine pairs, within which he experimentally gave extra food to one pair. The home range of this pair subsequently declined, and the young grew faster. In contrast, a study of Booted Eagles showed that breeding parameters were density independent (Martínez et al. 2006).

The occupancy rate of a nesting territory has been recently shown to be a consistent measure of territory quality in a wide range of species, including Black Kites (Milvus migrans) (reviewed by Sergio and Newton 2003; Sergio et al. 2007). In a 10-year study of Black Kites in the Lake Lugano area of Northern Italy, territory occupancy rate was clearly associated with breeding performance (Sergio and Newton 2003). In the current study on Red Kites, we also confirmed that the number of fledged young is influenced by both home range size (negative correlation) and territorial occupancy rate (positive correlation). 
The well-known "calendar effect," resulting in more young being produced by earlier breeding birds has also been described for the Red Kite (Schönbrodt and Tauchnitz 1987; Pfeiffer 2000). It was difficult to confirm this trend for the Red Kites, because only a limited number of individuals were tracked. In our study the proof was tight. Sergio et al. (2007) demonstrated that the breeding output of both male and female Black Kites declined with later arrival dates.

\section{Home range size in relation to the onset of incubation and food availability}

The occupancy rate of Black Kite territories in Northern Italy was non-random. Some territories were preferred, while others were avoided. On return from migration, males and females settled earlier on high-occupancy territories (Sergio and Newton 2003). In the current study, we did not investigate spring arrival in detail. However, we were able to infer the start of incubation of the first egg could be calculated from the age of young birds in 30 successful broods by 21 different males. This parameter is comparable to spring arrival, and we were able to demonstrate that home range size is correlated with the onset of incubation.

An important reason for the observed fluctuation in Red Kite home range size are differences in food availability. We demonstrated this phenomenon through the correlation between home range size and the nutritional condition of the young. If an adequate source of food is located close to the nest and is available throughout the complete breeding season (such as fish-rich reservoirs with richly-structured surroundings, commercial fish ponds or composting plants), the home range tends to remain small, according to our own field observations. It expands only slightly when grasslands were mowed or when cereal crops were harvested towards the end of the nestling period, as these activities increase the likelihood of locating prey at more distant locations from the nest. If such special habitat structures with high concentrations of animal prey are not available, the Red Kite must frequent a broader range of sites to obtain food. Yet, a shortage of food cannot always be compensated for by hunting flights at greater distances from the nest. For birds with very large home ranges, the biomass per time unit brought to the nest was clearly no longer sufficient to feed several young (Fig. 3). All seven Red Kite males in this study that managed to rear three (six cases) and four (one case) young had home ranges of less than $50 \mathrm{~km}^{2}$ during the nestling phase.

In addition, individual hunting skills and specialisation in certain types of prey are expected to influence the breeding success of individuals.

\section{Age and home range size}

The study on Sparrow Hawks shows that older, more experienced individuals occupy the best-quality sites, whereas younger individuals occupy low-quality sites (Newton 1986, 1998). This difference generates different breeding performances. Age has also been shown to cause significant differences in breeding performance in Peregrine Falcons (Zabala and Zuberogoitia 2014). An ongoing study on the Lesser Spotted Eagle (Aquila pomarina), which is slightly larger than the Red Kite, showed that the home ranges of old breeders range from very small to very large. In this study of two adult Lesser Spotted Eagle males of 20 and 24 years showed that the 20 year old bird had a very large home range $\left(128 \mathrm{~km}^{2} 90 \%\right.$ Kernel, $206 \mathrm{~km}^{2}$ MCP $95 \%$ ), whereas that of the 24 year old bird was very small (3.5 km² $90 \%$ Kernel, $3.2 \mathrm{~km}^{2}$ MCP $95 \%$ ) (Meyburg et al. unpubl.). This correlation was not evident in the current study, in which we tracked 12 successfully breeding Red Kites with known age.

\section{Comparison of home range sizes with other species}

Independent of the method selected to calculate the home range size of Red Kites, comparisons among different individuals, the same individual in different years, and in different parts of a reproduction phase demonstrate that area size was highly variable. This phenomenon has also been demonstrated for the Sparrow Hawk. Newton (1998) observed great variation in home range size of individual birds in a $200 \mathrm{~km}^{2}$ study area over a 10 -year period. He also documented unequal production among the territories of individuals.

To date, there is only one published GPS telemetry study on the home range size of the very closely related Black Kite (Meyburg \& Meyburg 2009). This study obtained the home range of an adult male Black Kite in Brandenburg, north of Berlin (Germany), during the complete 2008 breeding period and associated breeding success. The home range covered a $60.9 \mathrm{~km}^{2}$ area (MCP $95 \%$ ), based on 821 GPS fixes. Using the Kernel method, a home range of $121.24 \mathrm{~km}^{2}$ (95\% Kernel) was calculated. The bird was located at distances of up to $20.7 \mathrm{~km}$ from its nest. The size of the home range differed greatly across months.

Similar results were also obtained for Lesser Spotted Eagles fitted with GPS transmitters in northern Germany (Meyburg et al. 2006; Langgemach and Meyburg 2011). This species is of similar size to Red Kites, and has comparable feeding territory demands. The territories of four males tracked by GPS transmitters in a single breeding season were at least $32.78,34.14,46.4$, and $54.39 \mathrm{~km}^{2}$, 
respectively. A fifth male was studied over 2 years, and had home ranges of 93.78 and $172.29 \mathrm{~km}^{2}$ in 2005 and 2006, respectively. The mean of all six activity areas (i.e. the four territories of the first four males and the two territories of the fifth male) was $72.29 \mathrm{~km}^{2}$ (MCP $100 \%$ ) (Meyburg et al. 2006). The home range size of these males during the breeding period was not constant, but appeared to depend on the phase of the reproduction cycle and prey availability. Thus, the number of fledged young is influenced by both home range size (negative correlation) and the territorial occupancy rate (positive correlation).

In conclusion, home rage size serves as a reliable indicator of Red Kite habitat quality. For this species, home range size is dependent on food availability, and is strongly correlated with breeding success. Few published raptor studies have linked home range size to breeding success. Specifically, the scarcer the food supply is in the habitat, the larger the home range, and the poorer the breeding performance of Red Kites. The same results were obtained for the Sparrow Hawk, thus this correlation may also be true for other species. The assessment of the habitat quality in an indicator species, such as the Red Kite, provides key conservation information at the wider ecosystem level, bridging the gap between single species and ecosystem conservation. Successful conservation should maintain or improve high quality sites, rather than focusing on poor sites, leading to the deterioration of key areas. The analysis of space use patterns of large bird species using GPS telemetry presents a new challenge in science and nature conservation. Unsuitable methodology might provide wrong negative results, which must be avoided.

Acknowledgments This study took place in the framework of a project of the World Working Group on Birds of Prey (WWGBP) and was essentially funded by the Thuringia State Ministry for Agriculture, Forestry, Environment, and Nature Protection, as well as by the European Agricultural Fund for Rural Development (EAFRD) on the basis of the Förderinitiative ländliche Entwicklung in Thüringen (FILET), in particular the Förderung von Maßnahmen zur Entwicklung von Natur und Landschaft (ENL). The permits for the capture of the birds and their fitting with transmitters were issued by the Thuringia State Ministry for Agriculture, Forestry, Environment and Nature Protection. For their assistance in respect of the satellite transmitters we wish to thank Dr. P. Howey (Microwave Telemetry, Inc.), Dr. Th. Keller (ACOMED Statistik, Leipzig, Germany), for supporting the statistical evaluations and D. Conlin and Dr. G. Schofield (Write Science Right) for linguistic help and useful comments. We also thank Prof. Ian Newton and two anonymous referees for comments on previous drafts of the article.

Open Access This article is distributed under the terms of the Creative Commons Attribution 4.0 International License (http:// creativecommons.org/licenses/by/4.0/), which permits unrestricted use, distribution, and reproduction in any medium, provided you give appropriate credit to the original author(s) and the source, provide a link to the Creative Commons license, and indicate if changes were made.

\section{References}

Aebischer A (2009) Der Rotmilan: ein faszinierender Greifvogel. Haupt, Bern Stuttgart Wien

Burt WH (1943) Territoriality and home range concepts as applied to mammals. J Mammal 24:346-352

George K (1995) Neue Bedingungen für die Vogelwelt der Agrarlandschaft in Ostdeutschland nach der Wiedervereinigung. Ornithol Jahresber Mus Heine 13:1-25

Hovey FW (1999) Home Ranger version 1.5. Downloaded from http://nhsbig.inhs.uiuc.edu/wes/home_range.html. Accessed 6 July 2014

Kenward RE, Walls SS, South AB, Casey NM (2008) Ranges 8: For the analysis of tracking and location data. Online manual. Antrack Ltd., Wareham

Langgemach T, Meyburg B-U (2011) Funktionsraumanalysen - ein Zauberwort der Landschaftsplanung mit Auswirkungen auf den Schutz von Schreiadlern (Aquila pomarina) und anderen Großvögeln. Ber Vogelschutz 47(48):167-181

Mammen U, Stubbe M (1995) Alterseinschätzung und Brutbeginn des Rotmilans (Milvus milvus). Vogel u Umw 8:91-98

Mammen K, Mammen U, Resetaritz A, (2014) Rotmilan. In: Hötker $\mathrm{H}$, Krone O, Nehls G (eds) Greifvögel und Windkraftanlagen: Problemanalyse und Lösungsvorschläge. Schlussbericht für das Bundesministerium für Umwelt, Naturschutz und Reaktorsicherheit. Michael-Otto-Institut im NABU, Leibniz-Institut für Zoound Wildtierforschung, BioConsult SH, Bergenhusen, Berlin, Husum. https://bergenhusen.nabu.de/imperia/md/nabu/images/ nabu/einrichtungen/bergenhusen/projekte/bmugreif/endbericht_ greifvogelprojekt.pdf and https://bergenhusen.nabu.de/imperia/ $\mathrm{md} / \mathrm{nabu} /$ images/nabu/einrichtungen/bergenhusen/projekte/bmu greif/endbericht_greifvogelprojekt_anhang.pdf. Accessed 22 Mar 2015

Martínez JE, Pagán I, Calvo JF (2006) Interannual variations of reproductive parameters in a booted eagle (Hieraaetus pennatus) population: the influence of density and laying date. J Ornithol 147:612-617

Meyburg B-U, Fuller MR (2007) Satellite tracking. In: Bird DM, Bildstein KL (eds) Raptor research and management techniques. Hancock House Publishers, Surrey, pp 242-248

Meyburg B-U, Meyburg C (2009) GPS-Satelliten-Telemetrie bei einem adulten Schwarzmilan (Milvus migrans): Aufenthaltsraum während der Brutzeit, Zug und Überwinterung. In: Stubbe M, Mammen U (eds) Populationsökologie von Greifvogel- und Eulenarten 6. Halle/Saale, pp 243-284

Meyburg B-U, Meyburg C (2013) Telemetrie in der Greifvogelforschung. In: Falkenorden D (ed) Greifvögel und Falknerei 2013. Neumann-Neudamm, Melsungen, pp 26-60

Meyburg B-U, Meyburg C, Matthes J, Matthes H (2006) GPSSatelliten-Telemetrie beim Schreiadler Aquila pomarina: Aktionsraum und Territorialverhalten im Brutgebiet. Vogelwelt 127:12-144

Nachtigall W, Herold S (2013) Der Rotmilan (Milvus milvus) in Sachsen und Südbrandenburg. Jahresber Monitoring Greifvögel Eulen Europas 5. Sonderband:1-104

Nachtigall W, Stubbe M, Herrmann S (2010) Aktionsraum und Habitatnutzung des Rotmilans (Milvus milvus) während der Brutzeit-eine telemetrische Studie im Nordharzvorland. Vogel und Umw 18:25-61

Newton I (1979) Population Ecology of Raptors. Poyser, Berkhamsted

Newton I (1986) The Sparrowhawk. Poyser, Calton

Newton I (1998) The role of individual birds and the individual territory in the population biology of Sparrowhawks Accipiter 
nisus. In: Chancellor RD, Meyburg B-U, Ferrero JJ (eds) Holarctic Birds of Prey. ADENEX-WWGPB, pp 117-129

Pfeiffer T (2000) Über den Ernährungszustand juveniler Rotmilane in der Umgebung von Weimar und daraus abzuleitende Schutzvorschläge. Landschaftspflege und Naturschutz 37:1-10

Pfeiffer T (2009) Untersuchungen zur Altersstruktur von Brutvögeln beim Rotmilan Milvus milvus. In: Stubbe M, Mammen U (eds) Populationsökologie von Greifvogel- und Eulenarten 6. Halle/ Saale, pp 197-210

Pfeiffer T, Meyburg B-U (2009) Satellitentelemetrische Untersuchungen zum Zug und Überwinterungsverhalten Thüringischer Rotmilane Milvus milvus. Vogelwarte 47:171-187

Porstendörfer D (1994) Aktionsraum und Habitatnutzung beim Rotmilan Milvus milvus in Süd-Niedersachsen. Vogelwelt 115:293-298

Porstendörfer D (1998) Untersuchungen zum Aktionsraum des Rotmilans (Milvus milvus) während der Jungenaufzucht. Vogelkdl Ber Niedersachs 30:15-17

Schönbrodt R, Tauchnitz H (1987) Ergebnisse 10-jähriger Planberingung von jungen Greifvögeln in den Kreisen Halle, HalleNeustadt und Saalkreis. In: Stubbe M (ed) Populationsökologie von Greifvogel- und Eulenarten 1. Halle/Saale, pp 67-84

Seaman DE, Powell RA (1996) An evaluation of the accuracy of kernel density estimators for home range analysis. Ecology 77:2075-2085

Sergio F, Newton I (2003) Occupancy as a measure of territory quality. J Anim Ecol 72:857-865. doi:10.1046/j.1365-2656. 2003.00758.x
Sergio F, Blas J, Forero MG, Donazar JA, Hiraldo F (2007) Sequential settlement and site dependence in a migratory raptor. Behav Ecol 18:811-821. doi:10.1093/beheco/arm052

Steenhof K, Newton I (2007) Assessing nesting success and productivity. In: Bird DM, Bildstein KL (eds) Raptor research and management techniques. Hancock House Publishers, Surrey, pp 181-191

Traue H, Wuttky K (1966) Die Entwicklung des Rotmilans (Milvus milvus L.) vom Ei bis zum flüggen Vogel. Beitr Vogelkd $11: 253-275$

Walz J (2001) Bestand, Ökologie des Nahrungserwerbs und Interaktionen von Rot- und Schwarzmilan 1996-1999 in verschiedenen Landschaften mit unterschiedlicher Milandichte: Obere Gäue, Baar und Bodensee. Ornithol Jh Bad-Württ 17:1-212

Walz J (2008) Aktionsraumnutzung und Territorialverhalten von Rotund Schwarzmilanpaaren bei Neuansiedlungen in Horstnähe. Ornithol Jh Bad-Württ 24:21-38

Wasmund N (2013) Der Rotmilan (Milvus milvus) im Unteren Eichsfeld. Brutbestand, Nahrungsökologie und Gefährdungsursachen. Dissertation, Georg-August-Universität Göttingen (http://d-nb.info/1044871032/34)

Worton BJ (1989) Kernel methods for estimating the utilization distribution in home-range studies. Ecology 70:164-168

Zabala J, Zuberogoitia I (2014) Breeding performance and survival in the Peregrine Falcon Falco peregrinus support an age-related competence improvement hypothesis mediated via an age threshold. J Avian Biol. doi:10.1111/jav.00505 